\title{
Editorial: Passing the torch of Operations Management Research
}

\author{
Jan Olhager $^{1} \cdot$ Scott Shafer ${ }^{2}$ \\ Published online: 1 December 2018 \\ (C) Springer Science+Business Media, LLC, part of Springer Nature 2018
}

Time passes quickly when you are having fun. In January 2012, we accepted the responsibility to be the new editorsin-chief of Operations Management Research (OMR). The journal was established in 2008 with Jack Meredith and Patrick McMullen as editors-in-chief (Meredith and McMullen 2008). With a specific focus on bringing practice and theory together, $O M R$ has managed to position itself well among the operations management journals, promoting research that is relevant to both practitioners and researchers. The subtitle of the journal describes this relationship well: "Advancing practice through theory".

In our first editorial in 2012 (Olhager and Shafer 2012), we stated the following vision for the continuation of $O M R$ as a journal that:

- Does not compromise on rigor or relevance.

- Is valued and respected by both practitioners and academics.

- Fosters dialogue on contemporary issues.

We believe that we have lived up to this vision. One example of the last point is the special issue in 2016 on manufacturing reshoring, which was received very well by the academic community.

This year $O M R$ is celebrating ten years! A particular noteworthy accomplishment was the inclusion of the journal in Thomson Reuters ISI Web of Knowledge in 2012. The journal

Scott Shafer

shafersm@wfu.edu

Jan Olhager

jan.olhager@tlog.lth.se

1 Department of Industrial Management and Logistics, Lund University, Lund, Sweden

2 School of Business, Wake Forest University, Farrell Hall, Winston Salem, NC 27109, USA citation Impact Factor has been growing over the years, and is currently at 1.524 . This is a considerable achievement for such a young journal. Table 1 displays some additional journal measures for the last four years. While the number of submissions has increased, the number of papers that have been desk rejected has also increased. Thus, while the quantity of submitted papers has increased, the journal still faces a challenge related to the quality of submissions. The papers that are sent out for review stand a 50\% chance of ultimately being accepted - a number that has been relatively stable over the four years. Also consistent with the mission of the journal to provide fast turnaround times, we are pleased to report that the average time from submission to the first decision was generally less than one month over the most recent four-year period.

Now it is time for us to pass on the torch of $O M R$ for the next leg of the journal's operations (cf. McMullen and Meredith 2011). It has been a quite interesting journey, but all good things must come to an end. Looking back on our seven years as co-editors-in-chief, we find that there have been at least three key success factors for advancing $O M R$.

First, the most important aspect for the success of the journal is that the OM community continue to contribute to the journal by doing research with rigor and relevance for both theory and practice and submitting it to $O M R$. We want to thank all researchers who have submitted their quality research to $O M R$ over the years.

Second, the success of a journal is dependent on the commitment and support of the editorial board and the reviewers. Many of the Regional and Area Editors of $O M R$ have been with the journal the entire journey from its initiation in 2008. Our sincere thanks are hereby extended to all Area Editors and reviewers. We would also like to thank the founding editors and the members of the Editorial Oversight board for giving us the opportunity to be the co-editors-in-chief of $O M R$.

Third, we want to thank Springer for editorial support. In particular, Neil Levine and Matthew Amboy have been very 
Table 1 Journal statistics

\begin{tabular}{lllll}
\hline Measure & 2014 & 2015 & 2016 & 2017 \\
\hline Papers submitted & 204 & 206 & 252 & 251 \\
Papers desk rejected (\%) & 74.6 & 79.3 & 83.5 & 90.8 \\
Papers rejected (\%) & 13.9 & 10.6 & 7.3 & 4.2 \\
Accepted (\%) & 13.4 & 10.1 & 9.2 & 5.0 \\
Average time from initial submission to first decision (days) & 29.8 & 37.2 & 17.3 & 21.1 \\
Impact factor (ISI Web of Knowledge) & 0.737 & 0.632 & 0.800 & 1.524 \\
\hline
\end{tabular}

helpful over the years in promoting the journal and us in our position as co-editor-in-chief.

As we depart our co-editorship of this journal, we are certainly hopeful that the future of $O M R$ will continue to emphasize the marriage of practice and theory, and attract even higher levels of quality manuscripts and thereby make important contributions to both the theory and practice of OM.

Publisher's Note Springer Nature remains neutral with regard to jurisdictional claims in published maps and institutional affiliations.

\section{References}

McMullen PR, Meredith JR (2011) Editorial: passing on the torch of Operations Management Research. Oper Manag Res 4:87-88.

Meredith JR, McMullen PR (2008) Editorial: introducing operations management research: advancing practice through theory. Oper Manag Res 1:1-5.

Olhager J, Shafer S (2012) Editorial: the next leg for Operations Management Research. Oper Manag Res 5:1-2. 